\title{
THE EFFECT OF EXERCISE ON THE ELECTROCARDIOGRAM IN HEALTHY SUBJECTS
}

\author{
BY \\ H. G. LLOYD-THOMAS \\ From the Cardiac Department, the London Hospital \\ Received September 5, 1960
}

The diagnosis of coronary arterial disease may often be difficult. In most ambulant patients with such disease, clinical examination reveals no abnormal signs. Although a high proportion of patients who give a history regarded as classical of cardiac pain will show an abnormal electrocardiogram, it is known that a number have a normal tracing and that in some of these, the subsequent progress has proved that the pain had a non-cardiac source. Moreover, some patients whose subjective symptoms do not exactly conform with those identified with coronary arterial disease are later proved to have the disease. Having regard, therefore, to the not infrequent unreliability of the history, the sparsity of physical signs, and the uncertainty of some cardiographic changes while the patient is at rest, the exercise electrocardiogram has sometimes been regarded as a way of judging the real contribution that each can make to the diagnosis.

The exercise test is intended to determine the adequacy of the blood supply to the myocardium at a time when the demand for such a supply is increased temporarily by exercise. As its main purpose lies in the objective confirmation of the diagnosis of coronary arterial disease, it is imperative to know the natural changes that occur in healthy subjects after exercise. Because opinion is at variance on the interpretation of tracings recorded after exercise, there is need to define the kinds of change that unequivocally denote ischæmia of the myocardium and constitute a positive test. In this connection it is essential to recognize the effects that physical effort with its associated tachycardia can produce in electrocardiograms from normal subjects, and, on the other hand, to be familiar with the slight abnormalities that signify cardiac ischæmia. The purpose of this investigation is to contribute to the solution of this problem.

\section{Material AND Methods}

The investigation was carried out on 67 subjects who, following clinical, radiological, and electrocardiographic examination, were judged to be healthy. The analysis of the effects of exercise on the physiological electrocardiogram in health was made on the records obtained from this group. None of them gave a history of chest pain. All were free from abnormal physical signs, and the blood pressure was normal in each. Fluoroscopy of the heart and lungs was always normal. The electrocardiograms at rest were critically inspected and were found to be physiological in all; no subject showed any of the lesser signs of myocardial injury described by Evans and McRae (1952) and Evans and Pillay (1957). It is impossible to provide a group of normal subjects in this age group who are indisputably free from coronary atheroma. By the adoption of the rigid criteria of selection described, however, the incidence of coronary arterial disease in this group has been reduced to a minimum.

All the electrocardiographic records were taken with the patient in the semi-recumbent position. 
Normal standardization $(1 \mathrm{mv} .=1 \mathrm{~cm}$. deflection) was employed throughout. The leads used in each subject were the three standard limb leads, lead IIIR (lead III recorded during deep inspiration) and the chest leads CR1, CR4, and CR7. All the records were taken with the Elmqvist three-channel electrocardiograph. Tracings were taken before exercise, and at intervals of two, four, and ten minutes after completion of the exercise. In each instance the same seven leads were recorded. Particular importance was attached to the taking of records at intervals of four and ten minutes after exercise because several authors have recognized that the development of ischæmic patterns may be delayed (Levan, 1945; Wood et al., 1950; Holzman, 1952; Scherf and Boyd, 1953; Goldberger, 1953; and Manning, 1957).

An exercise test should be so arranged as to increase the demand for coronary blood flow to the point where any appreciable obstruction of the coronary arteries leads to a deficiency of blood supply. This stage varies not only from patient to patient, depending on factors other than age, weight, and sex, but also from time to time in the same patient. It seems unwise to prescribe a uniform amount of exercise as recommended by Master (1942), and Manning (1957) has been critical of the test as devised by Master (1929) because he found that 24 per cent of 200 very carefully investigated young men, aged 18 to 24 years and considered fit for full flying duties, would have to be regarded as abnormal according to the criteria that he set.

The exercise used in this investigation consisted of the repeated ascent and descent, at room temperature, of a two-step staircase, designed according to Master (1929), each step being nine inches high. The 67 subjects were asked to exercise in such a way that both the rate and the total amount of work would be approximately equal but would not exceed the maximum to which they would expose themselves during their ordinary everyday activities. They continued until they were halted by dyspnœa or fatigue. The majority exercised for three minutes. None developed chest pain.

Among the 67 cases 59 were men, of whom 14 were aged between 21 and 29 years, 8 between 30 and 39 years, 22 between 40 and 49 years, 13 between 50 and 59 years, and 2 were over 60 years of age. Four of the eight women were aged between 40 and 49 years, three between 50 and 59 years, and one was aged over 60 years. The average age of the men was 44 years and of the women 49 years.

\section{The Cardiographic Changes Described}

The $P$ Waves. The $\mathrm{P}$ waves after exercise usually show some increase in amplitude, and not infrequently, an increase in duration. These changes are seen particularly in leads II and III (Holzman, 1952). The increased amplitude of the wave in these leads has been related to deviation of the $\mathbf{P}$ wave axis to the right, and this in turn to a more depressed position of the diaphragm after exercise (Lepeschkin, 1951). This deviation may explain the fact that an inverted $P$ wave in lead III may become upright after effort. Evans (1951) found that the P wave became taller, on inspiration only, in 109 of 173 healthy subjects in whom the wave was upright in lead III.

Increased voltage of the $\mathbf{P}$ wave after exercise in the present series was common and it was most often observed in leads II and III; an obvious increase in one of these leads was observed in 25 subjects, a small increase in 19, and very little or no increase in 17 subjects. The increase was more obvious in the chest leads in three subjects. In five, in whom there was inversion of the $\mathbf{P}$ wave in lead III at rest, the wave became upright after exercise. Inversion of a P wave, upright at rest, occurred in lead III on one occasion.

Usually when the $\mathrm{P}$ wave became increased in amplitude, the increase affected both the right and left atrial components. Occasionally the change affected either one or other component predominantly (Fig. 1). In some cases, the right atrial component became smaller and if this effect was enough to make the wave iso-electric, the P-R interval in that lead appeared to be shorter.

Of the 25 cases that showed an obvious increase in the $P$ wave, 4 showed no alteration in the direction of the QRS axis, 13 a deviation of the axis to the right of from $1^{\circ}$ to $37^{\circ}$, and 7 a deviation to the left of up to $9^{\circ}$. 

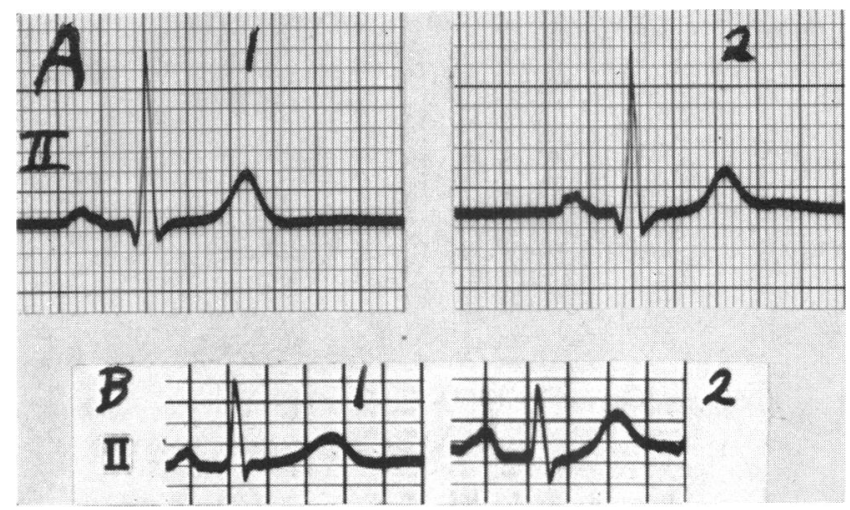

FIG. 1.-Electrocardiograms from healthy subjects (A and B); lead II, at rest (1) and two minutes after exercise (2). In both subjects the $P$ wave is increased after exercise; the change dominantly affects the right atrial component in A and the left atrial component in $\mathbf{B}$.
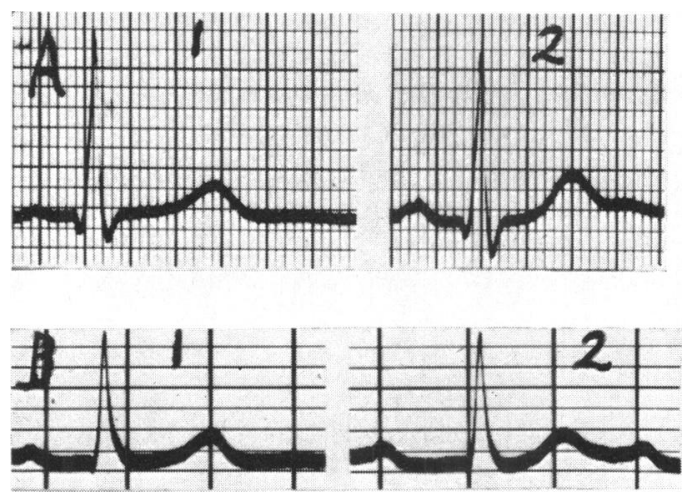

Fig. 2.-Electrocardiograms from two healthy subjects (A and B); lead II, at rest (1) and two minutes after exercise (2). (A) The P-R interval is increased slightly after exercise due to the presence of a larger $\mathbf{P}$ wave. (B) The $\mathbf{P}-\mathbf{R}$ interval is increased after exercise due to the longer $\mathbf{P}-\mathbf{R}$ segment.

The $P-R$ Interval. The $\mathrm{P}-\mathrm{R}$ interval or $\mathrm{P}-\mathrm{Q}$ interval, measured from the beginning of the $P$ wave to the onset of the $R$ wave or the $Q$ wave respectively, usually remains unaltered after exercise, or there may be a slight shortening of between 0.01 and 0.02 second (Holzman, 1952). The same author has observed that a slight prolongation of the interval may be a normal reaction where the beginning of the $P$ wave is indistinct at rest. Such an increase does not cause the P-R interval to exceed 0.22 second (Lepeschkin, 1951).

No alteration of the $P-R$ interval, measured correct to the nearest 0.01 second, was observed in 53 of the 67 cases. In eleven cases, the $P-R$ interval was increased, due to larger $P$ waves in seven and to longer P-R segments in four cases (Fig. 2). The P-R interval became shorter in three, and in each this was due to diminution of the size of the $P$ wave, the initial portion of the right atrial component having become iso-electric.

The $P-Q$ Segment. The $\mathrm{P}-\mathrm{Q}$ segment is the portion that joins the end of the $\mathrm{P}$ wave to the start of the QRS complex. The segment usually shows depression after exercise. This has been 
regarded as being due to accentuation of the atrial $T$ wave. According to current theory, the area subtended by the $P$ wave is equal in size but opposite in polarity to the area of the Ta wave. As the Ta wave shortens with tachycardia, it must deepen in order to keep its area equal to and opposite to that of the $P$ wave (Scherf and Schaffer, 1952). This effect should theoretically be larger if the amplitude of the $P$ wave increases.

In the series investigated, slight depression of the $P-Q$ segment developed in 38 , and greater depression in 25 subjects. In four, no change in the level of the $P-Q$ segment could be detected.

In the 25 showing marked depression of the $\mathrm{P}-\mathrm{Q}$ segment, this change was more obvious in lead II in 11 (Fig. 3) and in the chest leads in 12 cases. Conspicuous depression of the P-Q segment

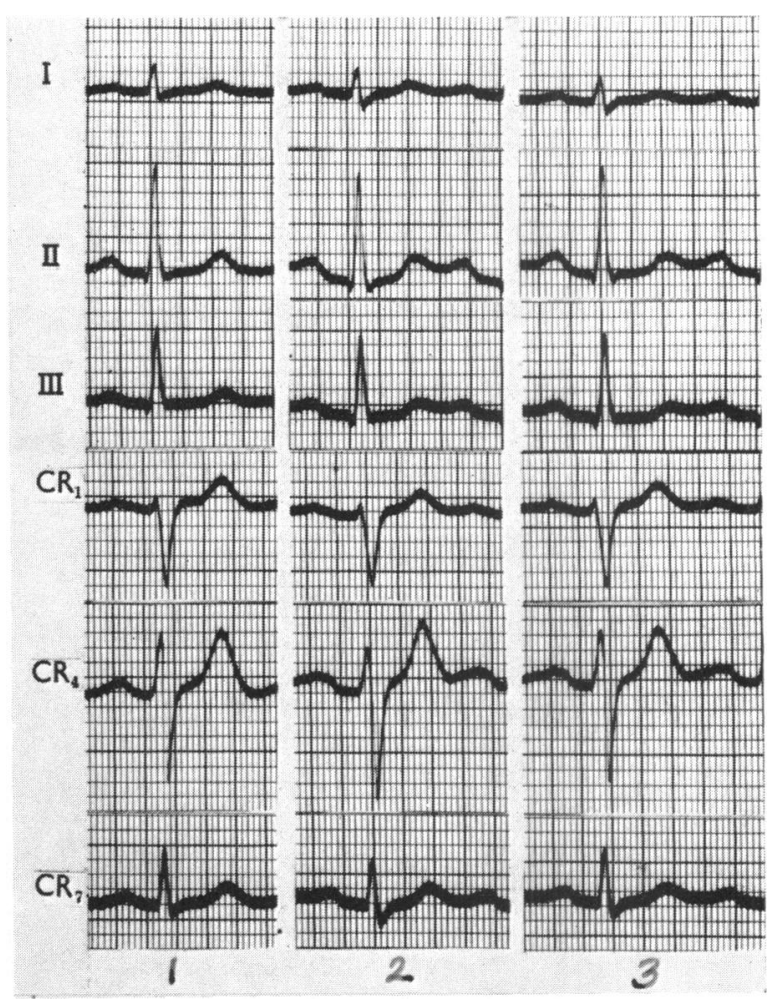

FIG. 3.-Electrocardiogram from a healthy subject at rest (1) and at intervals of two minutes (2) and four minutes (3) after exercise. The atrial $T$ wave is more obvious in lead II.

was observed in either lead CR4 or lead CR7 in 16 and in all the recorded leads in 3 cases. Wood et al. (1950) found that marked depression of the P-Q segment causing corresponding depression of the S-T segment was most common in lead II, but it was uncommon in left ventricular surface leads.

Of the 25 subjects who developed obvious depression of the $\mathrm{P}-\mathrm{Q}$ segment, 15 showed a distinct increase in the voltage of the $P$ wave and 8 showed either no, or only a slight, increase. In the remaining 2, the $\mathbf{P}$ wave inverted in lead III at rest became upright after exercise.

No subject showed elevation of the $\mathbf{P}-\mathbf{Q}$ segment in the presence of an upright $\mathbf{P}$ wave, nor a depression in the presence of an inverted $P$ wave.

The QRS Complex. Changes in the duration of the $\mathrm{QRS}$ complex cannot as a rule be determined with certainty when the usual electrocardiographic technique is used. Using film velocities of 
$100-150 \mathrm{~mm}$. per second it can be shown that the QRS duration may be reduced by two milliseconds after exercise (Lepeschkin, 1951). The QRS axis frequently deviates to the right after exercise (Scherf and Schaffer, 1952), but it is rare for the axis to be deflected to the left in healthy subjects (Holzman, 1952). Although alterations of the $\mathrm{R}$ waves and $\mathrm{S}$ waves may be partly related to changes in the QRS axis, other factors are involved.

In the present series, the QRS interval showed no measureable decrease, nor did it become significantly prolonged in any case. There was no alteration of the axis of the QRS in 13 subjects, a deflection to the right in 43 , and to the left in 11 subjects.

The configuration of the QRS complex in lead CR4 was such that the $R$ wave was larger than the $S$ wave in 51, equal to the $S$ wave in 2, and smaller in 14 subjects. After exercise, 20 showed a reduction in height of the $R$ wave not exceeding $1 \mathrm{~mm}$., 21 a loss of $2 \mathrm{~mm}$., 11 of $2-3 \mathrm{~mm}$., 2 of 4-6 mm., and in 1 case only a loss of $10 \mathrm{~mm}$. An increase in size of the R wave of $2 \mathrm{~mm}$. was observed in five subjects, of 2-4 mm. in four, of 4-6 mm. in two and of $12 \mathrm{~mm}$. in one case.

When the total amplitude of the QRS complex in lead CR4 was considered, there was no alteration in 4 subjects, an increase of $R$ wave balanced by an equal loss of $S$ wave in 22, a gain in amplitude due to increase of both $R$ and $S$ waves in 12, and a gain due to larger $R$ waves in 3 subjects. A reduction in amplitude of the complex occurred in 18 cases, in all of which it was due to diminution in the size of the $R$ wave. In no case did the $R$ wave decrease below a value representing 64 per cent of its height at rest. No subject developed a very low $R$ wave in this lead.

The S-T Segment. The junction of the QRS complex and the S-T segment is referred to as "J" (Fig. 4). In the tachycardia that follows exercise, there is a tendency for the $\mathrm{T}$ wave to become

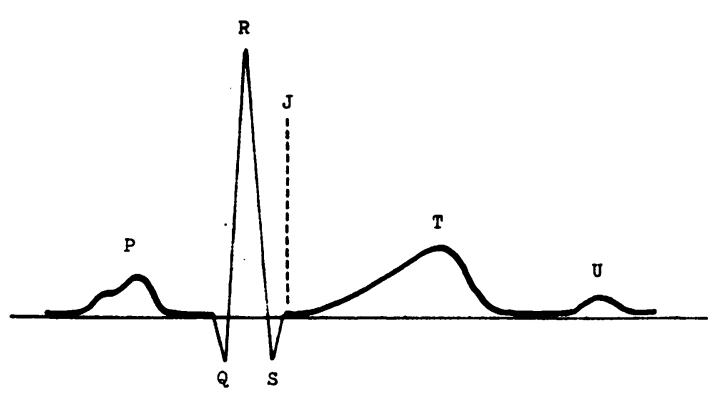

Fig. 4.-Diagrammatic tracing, showing atrial and ventricular complexes, to illustrate the position of $J$.

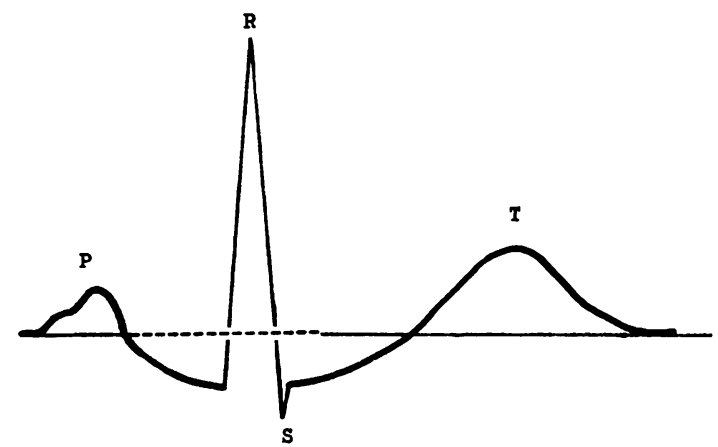

Fig. 5.-Diagrammatic representation of an accentuated atrial $\mathrm{T}$ wave ( $\mathrm{Ta}$ or $\mathrm{Tp}$ wave), which may persist beyond the $Q R S$ complex to produce corresponding depression of the early portion of the $S-T$ segment as well as depression of the $P-Q$ segment. The duration of the atrial $\mathrm{T}$ wave is represented by the dotted line.

joined to the $P$ wave of the following beat. Furthermore, exercise frequently increased the voltage of the $U$ wave leading to a still greater elevation of the $T-P$ segment. In these circumstances, comparison of the level of the $\mathrm{J}$ with this elevated T-P segment gives an erroneous appearance of $\mathrm{S}-\mathrm{T}$ depression. It is, therefore, essential that the level of the $\mathrm{J}$ should be judged in relation to the point where the $\mathrm{P}-\mathrm{Q}$ segment meets the $\mathrm{QRS}$ complex.

It is important when studying the configuration of the S-T segment that two or preferably three complexes recorded on a steady base-line should be available for analysis in each lead. Care should be taken not to include in measurement of the duration of the S-T segment, a portion of the QRS that is iso-electric. When simultaneous leads are recorded, it is usually simple to detect that an iso-electric portion of the tracing is occurring during the time of the $\mathrm{S}$ wave. When a single channel machine is used, greater care is required (Fig. 6 and 9). 


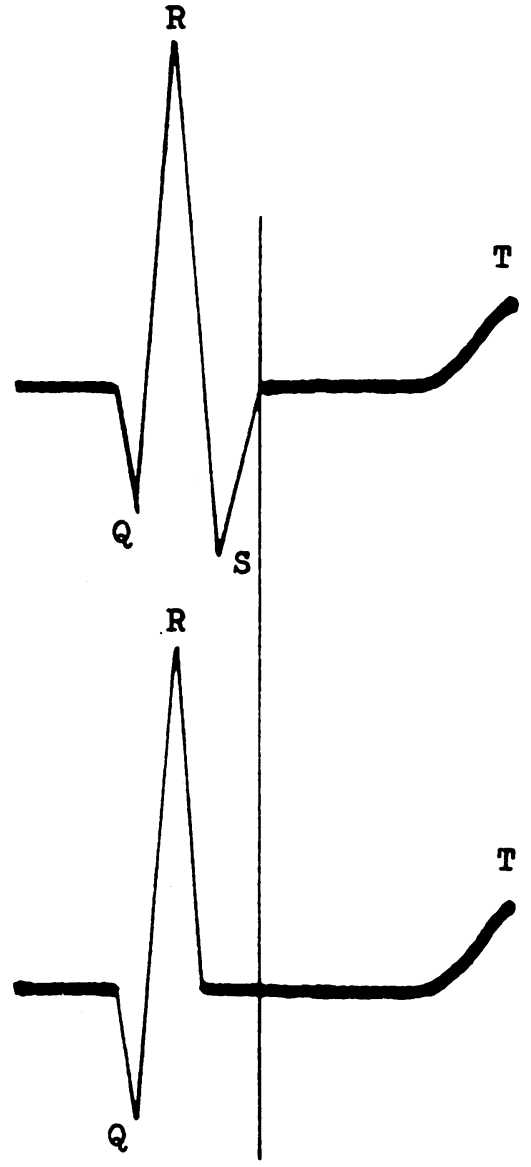

FIG. 6.-Diagram to show that where part of the QRS complex is iso-electric, the effect is to make the measured S-T segment appear prolonged. This effect is more easily discerned when simultaneous leads are recorded. The beginning of the S-T segment coincides with the vertical line in each tracing.

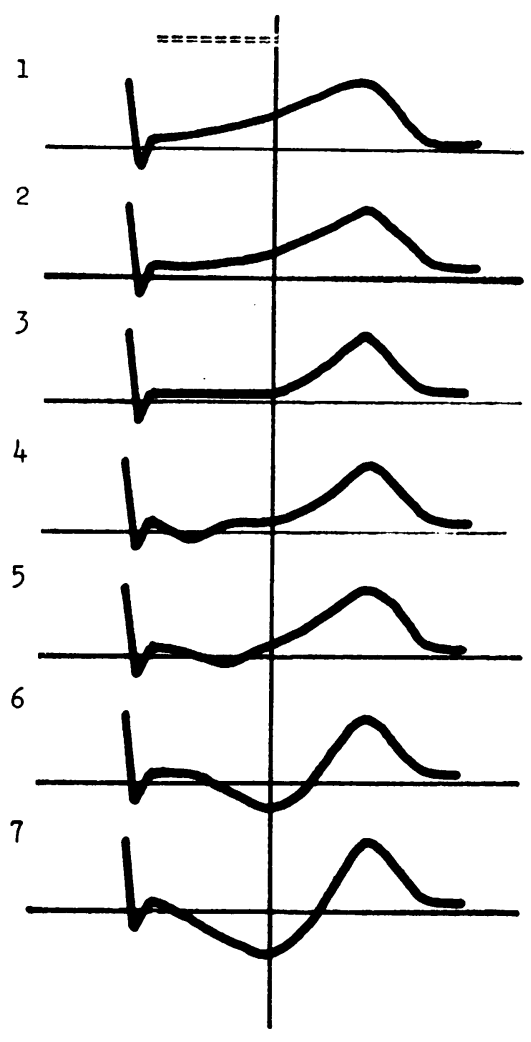

Fig. 7.-Diagram to illustrate the differing configurations of the S-T segment (indicated by the dotted line). Rapid rise (1), slow rise (2), plane (3), and sagging $(4,5,6,7)$.

Practically all authors are convinced of the importance of alterations in the S-T segment in the diagnosis of myocardial ischæmia. A good deal of discussion has centred on the distinction between the changes in the S-T segment to be expected in healthy subjects and those that indicate inadequate coronary blood flow. A further problem is the relative importance of depression of the $J$ and of the configuration of the $S-T$ segment as separate features.

It is necessary in the first place to appreciate the changes in the S-T segment that may occur with tachycardia alone. These are partly due to the enhanced atrial $\mathrm{T}$ wave (Fig. 5), an effect that had been observed by Einthoven in 1908. Most authors would regard a depression of the J, considered in relation to the $\mathrm{P}-\mathrm{Q}$ segment, in excess of $1 \mathrm{~mm}$. as abnormal, and almost all would agree that a depression of $2 \mathrm{~mm}$. is pathological in the absence of a very tall $R$ wave (Holzman, 1952). Wood et al. (1950) have, however, asserted that since depression of the $\mathrm{J}$ is a finding in normal subjects, there is no point in trying to distinguish between normal and ischæmic subjects on this ground. 
In the present series, there was no depression of $J$ relative to the $P-Q$ segment in 29 of the 67 subjects: 28 showed such a depression to the extent of $0.25 \mathrm{~mm}$. or less, 8 to $0.5 \mathrm{~mm}$., and 2 to $0.75 \mathrm{~mm}$. None showed a depression of $1.0 \mathrm{~mm}$. or more below the P-Q segment.

The normal configuration of the S-T segment in the electrocardiogram at rest is familiar. Having previous knowledge that the segment is commonly changed in the presence of coronary arterial disease, and, in order to assess the kind of change that is to be regarded as pathological, it was necessary to seek these abnormal varieties in the exercise tracings in this series of normal subjects. Included in such changes were depression in any of the three parts of the segment, early, middle, and late, giving rise to the kinds of S-T segment described as trough, plane or wing depression by Evans and McRae (1952). Twiss and Sokolow (1942) were among the first to comment on flattening of the main portion of the S-T segment in electrocardiograms at rest or after exercise in their patients with classical cardiac pain. Puddu (1939) had previously called attention to the change in the angle between the $\mathrm{S}-\mathrm{T}$ segment and the ascending limb of the $\mathrm{T}$ wave after exercise in patients with coronary arterial disease.

When the S-T segment in this normal group was analysed, it was apparent that its configuration

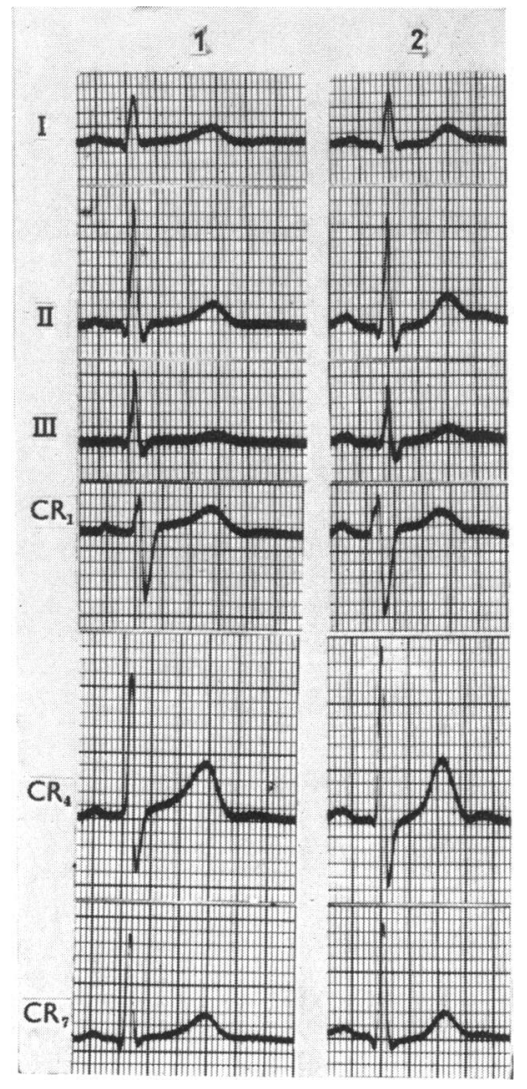

Fig. 8.-Electrocardiogram from a healthy subject before (1) and two minutes following exercise (2). The S-T segment after exercise shows a fairly rapid ascent.

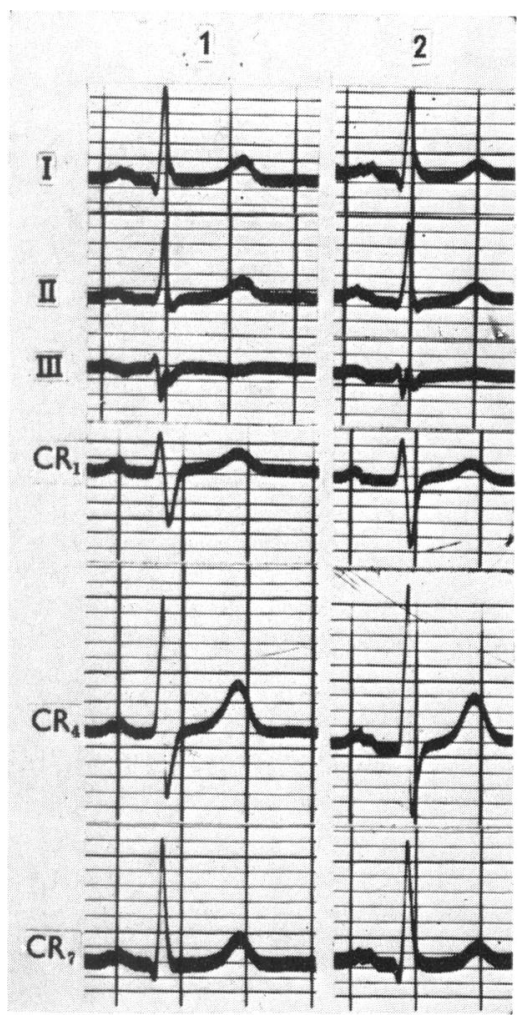

FIG. 9.-Electrocardiogram from a healthy subject before (1) and two minutes after exercise (2), showing slow ascent of the $S-T$ segment in lead CR7. A portion of the QRS complex in lead CR7 is iso-electric, producing an apparent increase in the duration of the $S-T$ segment. 
conforms to some four designs (Fig. 7). The first shows a fairly rapid rise, with an obviously concave upper border, to the peak of the $\mathrm{T}$ wave (Fig. 8). In the second, the segment rises slowly, but it retains its upper concave outline (Fig. 9). The remaining two designs in this group of normal subjects were found in leads III and IIIR alone. In the third, the rise is delayed so that S-T segment remains flat for a prolonged period, producing a plane (or horizontal) configuration (Fig. 10). In the fourth, there is descent of the $S-T$ segment from the level of the $J$ with the production of a sagging configuration (Fig. 11).

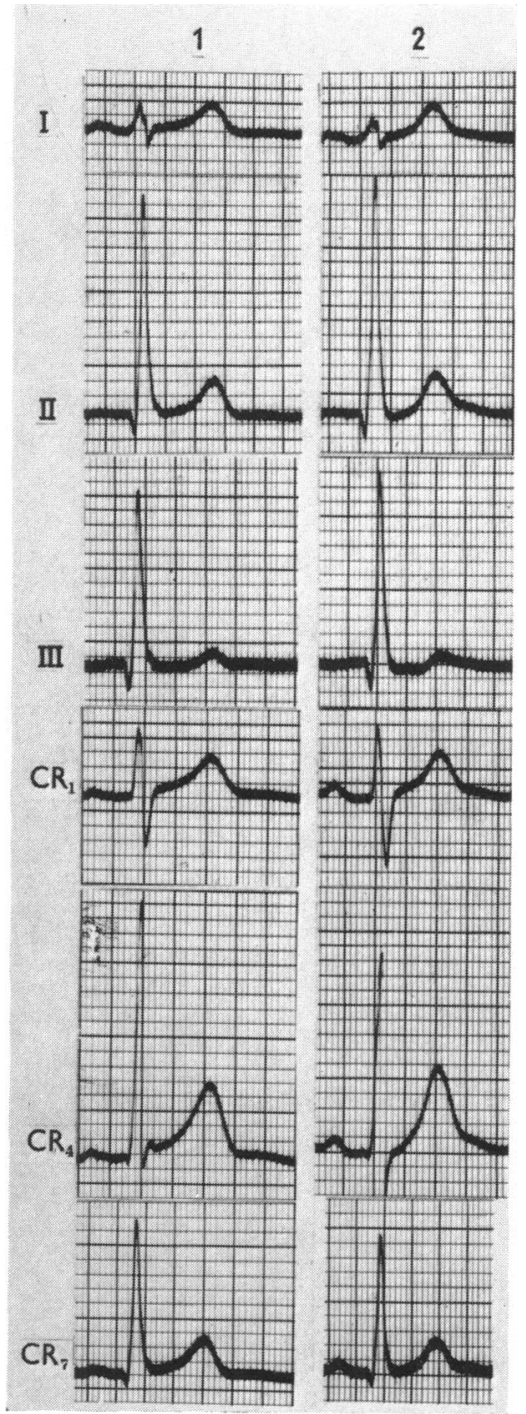

Fig. 10.-Electrocardiogram from a healthy subject before (1) and two minutes after exercise (2). The S-T segment in lead III developes a plane configuration.

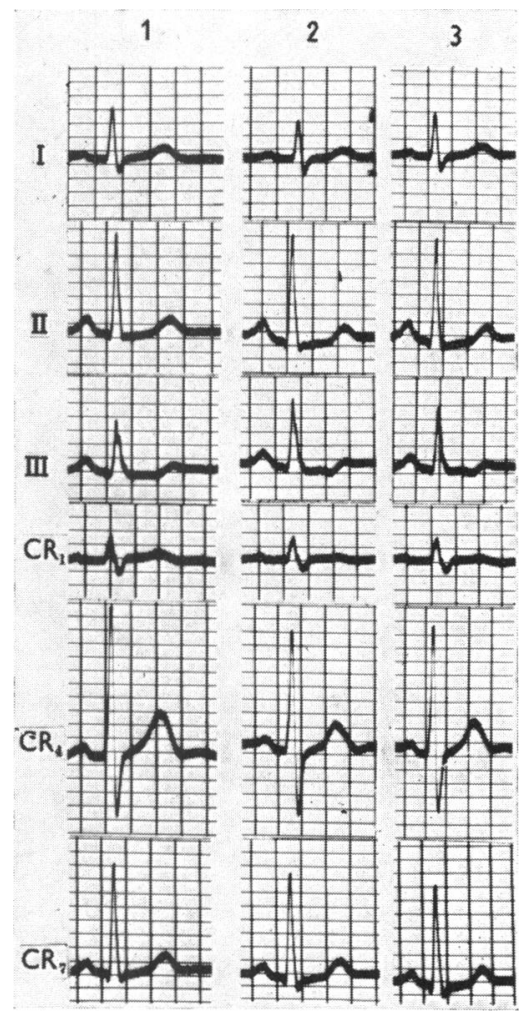

Fig. 11.-Electrocardiogram from a healthy subject before (1) and at intervals of two minutes (2) and four minutes (3) after exercise. The S-T segment in lead III shows a sagging configuration after effort. Lead V1 at rest showed an $R$ wave of $2 \mathrm{~mm}$. and an $S$ wave of $6 \mathrm{~mm}$. 
If leads III and IIIR are excluded from the analysis, none of the healthy subjects developed a sagging S-T segment, nor did any show an S-T segment that was plane for 0.08 second or longer. In seven subjects, the S-T segment showed a slow rise, affecting leads I and CR7 in two, lead II in one, and lead CR7 alone in four cases.

The S-T segment in lead III showed a plane configuration after exercise in this lead alone in 10 , and a sagging configuration in this lead alone in a further 5 subjects. Elevation of the S-T segment amounting to $0.5 \mathrm{~mm}$. or more was not observed after exercise in any healthy subject.

Chelton and Burchell (1955) found that the effect of exercise, on subjects who did not have heart disease but showed elevation of the S-T segment of $1 \mathrm{~mm}$. or more at rest, was to cause the S-T segment to return to the iso-electric level. They considered that the elevation at rest was due to early repolarization of the subepi-myocardium before completion of ventricular depolarization.

The $T$ Wave. Most authors have accepted that the inversion after exercise of a $T$ wave upright at rest is abnormal (Whitten and Herndon, 1938; Schott, 1939; Mazar, 1944; Biörck, 1946; Twiss and Sokolow, 1942; Levan, 1945; Grossman et al., 1949; Yu, 1951; Wood et al., 1950; Holzman, 1952; Goldman, 1956; and Marriott, 1957), but more recently others have ascertained that inversion of the T wave after exercise may occur in healthy subjects (Goldberger, 1953; Manning, 1957; and Rosen and Gardberg, 1957), while some (Robb et al., 1956) have found that the death rate from coronary arterial disease and the incidence of coronary occlusion are not significantly higher in those subjects showing only $\mathrm{T}$ wave changes, including inversion, after exercise compared with those

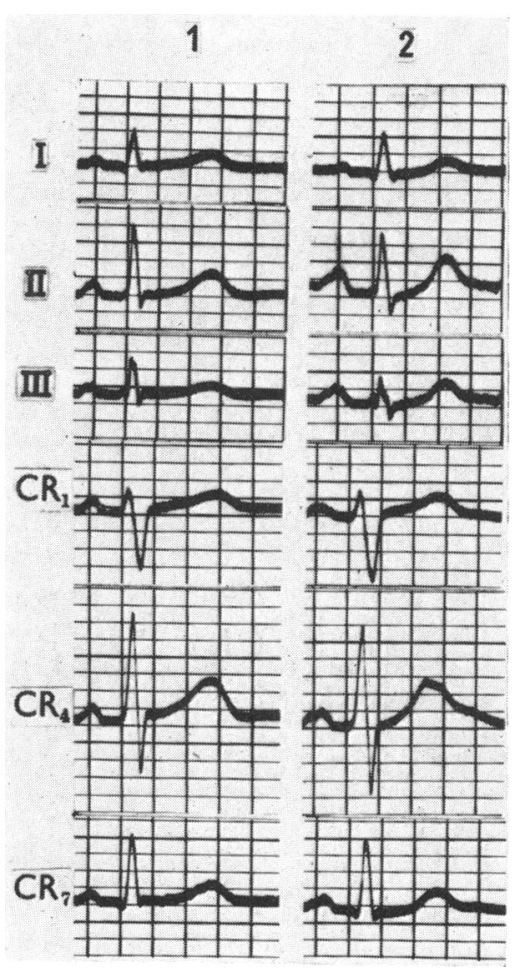

FIG. 12.-Electrocardiogram from a healthy subject before (1) and two minutes after exercise (2). Deformity of the T wave in lead CR4 developed after effort.

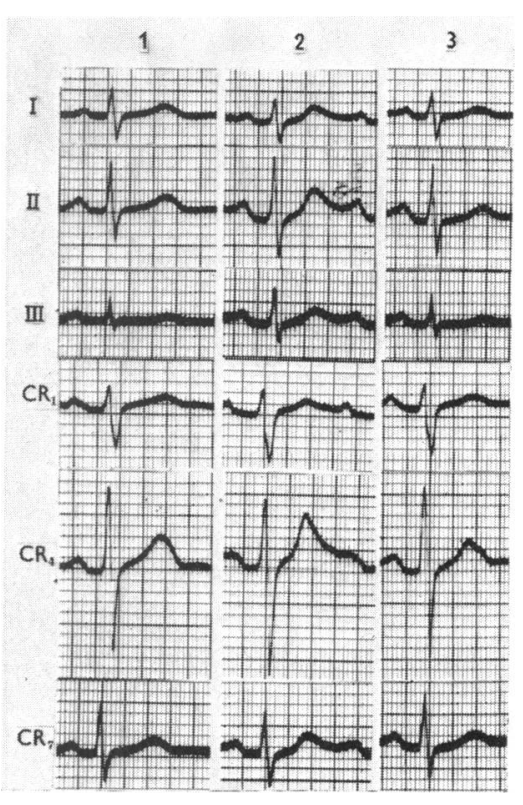

FIG. 13.-Electrocardiogram from a healthy subject before (1) and at two minutes (2) and four minutes (3) after exercise. The $T$ wave in lead CR4 is deformed after exercise. 
showing strictly normal responses. Because of the variability of the effect of exercise on the $T$ wave in lead III, many authors have disregarded such changes in this lead (Schott, 1939; Master, 1950; Twiss and Sokolow, 1942; Grossman et al., 1949; Goldman, 1956; Acheson, 1957; and Manning, 1957).

In the present series, a reduction of the amplitudes of the $T$ wave was common. Such reduction was 50 to 67 per cent in fifteen, 31 to 49 per cent in fourteen, 21 to 30 per cent in twelve, 11 to 20 per cent in seven, 10 per cent in one, and 0 to 5 per cent in eighteen subjects. A flat $T$ wave was not met with once. A $T$ wave that measured less than 10 per cent of the amplitude of the $R$ wave of the same complex was regarded as being of low voltage and this was found in nine subjects, affecting lead I alone in three, leads I and CR7 in two, the three standard limb leads in one, lead CR7 alone in one, and lead III alone in two subjects.

Inversion of a $T$ wave, that was upright in the tracing a trest, did not take place after exercise in any case in this series. An inverted $T$ wave in lead III became upright after exercise in six cases. Deformity of the $\mathrm{T}$ wave, which became blunt or bifid, in lead CR4 developed in the tracings recorded after exercise in three subjects aged 34, 43, and 26 years (Fig. 12 and 13).

The $U$ Wave. Inversion of the $\mathrm{U}$ wave after exercise was considered to be pathological by Palmer (1948): it did not develop after exercise in any of the subjects in this investigation. Its amplitude increased in several leads in 42 and in all leads in 1 case. In 12, the amplitude showed no obvious alteration, and in the remaining 12 it either decreased or became indiscernible owing to proximity of the $\mathrm{T}$ and the $\mathrm{P}$ waves from tachycardia.

The T-U Segment. Depression of the T-U segment in the electrocardiogram at rest in patients with cardiac pain was described by Evans and Pillay (1957). No case in this series developed such depression after exercise. Owing to the tachycardia following exercise it is necessary to relate the level of the T-U segment to the P-Q segment.

Extrasystoles and Conduction Defects. Although they were previously regarded as significant, more recently it has been thought that the occurrence of transient arrhythmias and conduction defects are of little diagnostic value (Master, 1957; and Robb et al., 1956). Extrasystoles, absent in the resting electrocardiogram, occurred in seven cases of this series. In four they were of ventricular origin, in two of atrial, and in one of nodal origin.

\section{SUMMARY AND CONCLUSIONS}

The exercise electrocardiogram was recorded in 67 healthy subjects. The exercise was strenuous, but it was always commensurate with the subject's ability to carry it out to the stage of breathlessness or fatigue; in none did it produce chest pain.

A resting electrocardiogram was first recorded, followed by three tracings at intervals of two, four, and ten minutes after the exercise. Attention was paid to changes in the $\mathbf{P}$ wave, $\mathbf{P}-\mathbf{R}$ interval, P-Q segment, QRS complex, S-T segment, T wave, T-U segment, and the $U$ wave, together with the appearance of an arrhythmia.

The investigation was carried out with a prerequisite knowledge of the lesser electrocardiographic changes identified with coronary arterial disease, and these were deliberately sought for in the tracings recorded after exercise.

With the exception of lead III, which is regarded as an unreliable lead in the exercise test, the undermentioned changes were not met with in any of the healthy subjects in this series. Thus, provided the $R$ wave was not tall (exceeding $20 \mathrm{~mm}$.) the point $\mathrm{J}$ was never depressed more than $1 \mathrm{~mm}$. below the P-Q segment. The S-T segment never showed a plane or sagging configuration: a plane depression was taken as being present if the S-T segment measured from the end of the $\mathrm{S}$ wave to the beginning of the $T$ wave remained flat for a period of $0 \cdot 1$ second. A previously upright $\mathrm{T}$ wave never became flat or inverted, the $\mathrm{T}-\mathrm{U}$ segment was never depressed below the $\mathrm{P}-\mathrm{Q}$ segment, the $U$ wave never became inverted, and the $R$ wave in lead CR4 never decreased to below 60 per cent of its voltage at rest. 
Acheson, E. D. (1957). Lancet., 1, 26.

\section{REFERENCES}

Biörck, G. (1946). Brit. Heart J., 8, 17.

Chelton, L. G., and Burchell, H. B. (1940). Amer. J. med. Sci., $230,54$.

Evans, W. (1951). Brit. Heart J., 13, 457.

-, and McRae, C. (1952). Brit. Heart J., 14, 429.

, and Pillay, R. K. (1957). Brit. Heart J., 19, 366.

Goldberger, E. (1953). Unipolar Lead Electrocardiography and Vectrocardiography. H. Kempton, London.

Goldman, M. J. (1956). Principles of Clinical Electrocardiography. Lange Medical Publications, Los Altos, California.

Grossman, M., Weinstein, W. W., and Katz, L. N. (1949). Ann. intern. Med., $50,387$.

Holzman, M. (1952). Clinical Electrocardiography. Staples Press, London.

Levan, J. B. (1945). War Medicine, 7, 353.

Manning, G. W. (1957). Amer. Heart J., 54, 823.

Marriott, H. J. L. (1957). Practical Electrocardiography. Baillière, Tindall, and Cox, London.

Master, A. M. (1950). Ann. intern. Med., 32, 842.

-, Field, L. E., and Donoso, E. (1957). New York J. Med., 57, 1051.

, Friedman, R., and Dack, S. (1942). Amer. Heart J., 24, 777.

_, and Oppenheimer, E. T. (1929). Amer. J. med. Sci., 177, 223.

Lepeschkin, E. (1953). 25th Scientific Session, American Heart Assn., 76

- (1951). Modern Electrocardiography. Baillière, Tindall, and Cox.

Mazer, M., and Reisinger, J. A. (1944). Ann. intern. Med., 21, 645.

Palmer, J. H. (1948). Brit. Heart J., 10, 247.

Robb, G. P., Marks, H. H., and Mattingly, T. W. (1956). Trans. Ass. Life Insur. med. Dir. Amer., 40, 52.

Rosen, I. L., and Gardberg, M. (1957). Amer. Heart. J., 53, 494.

Scherf, D., and Boyd, L. J. (1946). Clinical Electrocardiography. Lippincott, Philadelphia.

- and Schaffer, A. I. (1952). Amer. Heart J., 43, 927.

Schott, A. (1939). Guy's Hosp. Reports, 89, 347.

Twiss, A., and Sokolow, M. (1942). Amer. Heart J., 23, 498.

Whitten, M. B., and Herndon, J. H. (1938). Unpublished data quoted by Missal, M. E. (1938-39). Ann. intern. Med., 11, 2018.

Wood, P., McGregor, M., Majidson, C., and Whittaker, W. (1950). Brit. Heart J., $12,363$.

Yu, P. N. G., Bruce, R. A., Lovejoy, F. W., and McDowell, M. E. (1951). Circulation, $3,368$. 